\title{
EVALUATION OF THE CARRYING CAPACITY OF RECTANGULAR STEEL-CONCRETE COLUMNS
}

\author{
Glib VATULIA ${ }^{1, *}$, Maryna REZUNENKO ${ }^{1}$, Dmytro PETRENKO ${ }^{1}$, \\ Sergii REZUNENKO \\ ${ }^{1}$ Ukrainian State University of Railway Transport, Kharkiv, Feyerbakha Sq. 7, Kharkiv, Ukraine, \\ 61050 \\ ${ }^{2}$ Kharkiv National V.N. Karazin University, Svody Sq. 4, Kharkiv, Ukraine, 61022. \\ corresponding author: glebvatulya@gmail.com.
}

\section{Abstract}

Experimental studies of rectangular steel-concrete columns under centric compression with random eccentricity were conducted. The stress-strain state and the carrying capacity exhaustion have been assessed. The regression dependence is proposed to determine the maximum carrying capacity of such columns. The mathematical model takes into account the combined influence of the physical and geometric characteristics of the columns, such as their length, crosssectional area, casing thickness, prism strength of concrete, yield strength of steel, modulus of elasticity of both steel and concrete. The correspondence of the obtained model to the experimental data, as well as the significance of the regression parameters are confirmed by the Fisher and Student criteria.
\end{abstract}

\section{Keywords:}

Carrying capacity; Steel-concrete column; Centric compression; Statistical analysis; Mathematical model.

\section{Introduction}

Complex steel-concrete elements in the form of concrete-filled steel tubes (CFST) of various shapes have been commonly used in the current construction practice as effective high-strength and technological structures. The experience in the use of concrete tubes structures has proved the costeffectiveness of their application in the design of carrying elements of civil and industrial buildings vs. the conventional steel and concrete or metal structures [1 - 8].

Numerous experimental studies of such columns executed in the last forty years by researchers in many countries provide the basis for deduction development of the analytical dependence of the carrying capacity of columns on their geometric characteristics, such as cross-sectional dimensions, casing thickness and length, as well as physical and mechanical characteristics of materials, such as strength and modulus of elasticity of the concrete core, yield strength and modulus of elasticity of the steel casing. The mathematical model allows to shorten significantly the time for calculating the carrying capacity value depending on the characteristics of the columns.

The objective of this article is developing a mathematical model for evaluation of the influence of various factors on the carrying capacity of rectangular steel-concrete columns under centric compression with random eccentricity. The relevant studies on circular steel-concrete columns are presented in the paper [9].

The authors used the correlation and regression analysis for total 106 investigated samples to solve the problem. The dependence is based on the experimental data obtained in the laboratories of the leading countries of the world. The study involved samples with the characteristics as follows: casing thickness $t \geq 2.0 \mathrm{~mm} ; 76 \leq b \leq 360 \mathrm{~mm}$; ratio $L / b \geq 4$, at $500 \leq L \leq 4000 \mathrm{~mm}$; yield strength of steel $200 \leq \sigma_{y} f_{y} \leq 490 \mathrm{MPa}$; modulus of elasticity of steel $1.68 \cdot 10^{5} \leq E_{s} E_{a} \leq 2.17 \cdot 10^{5} \mathrm{MPa}$, prism strength of concrete $10 \leq f_{c, \text { prizm }} \leq 95 \mathrm{MPa}$, modulus of elasticity of concrete $2.0 \cdot 10^{4} \leq E_{c}$ $\leq 4.4 \cdot 10^{4} \mathrm{MPa}$.

Based on the data from the experiments done by the American and Japanese researchers, the following regression equation was obtained: 


$$
\begin{aligned}
& \bar{N}=a_{0}+a_{1} b h f_{\text {owirm }}+a_{2} \frac{L f_{\text {ceprim }}}{(b-2 t)(h-2 t)}+a_{3} \frac{t \sigma_{y}}{E_{s}}+a_{4}(b-2 t)(h-2 t) t= \\
& =71.481+8.64 \cdot 10^{-4} b h f_{\text {caprim }}-42.534 \frac{L f_{\text {sqwirm }}}{(b-2 t)(h-2 t)}+78.996 \frac{t \sigma_{y}}{E_{s}}+ \\
& +2.43 \cdot 10^{-3}(b-2 t)(h-2 t) t \text {. }
\end{aligned}
$$

Determination coefficient $R^{2}$ for the model is 0.997 , meaning approximation error is:

$\Delta=\frac{1}{n} \sum_{i=1}^{n} \frac{\left|N_{\operatorname{map}}-N_{\text {theror }}\right|}{N_{\operatorname{sxp}}} 100 \% \approx 5.92 \%$

Confidence intervals with probability $P=0.95$ were found for each coefficient to answer the question how much the obtained regression coefficients may differ from the exact values:

- $34.745 \leq a_{0} \leq 108.217$;

- $8.3 \circ 10^{-4} \leq a_{1} \leq 8.9 \circ 10^{-4}$;

- $-47.743 \leq a_{2} \leq-37.324^{3}$

- $73.682 \leq a_{3} \leq 84.309$;

- $1.9 \circ 10^{-3} \leq a_{4} \leq 2.9 \circ 10^{-3}$.

The correspondence of the obtained model to the experimental data, as well as the significance of the regression parameters are confirmed by the Fisher and Student criteria, respectively.

Fig. 1 shows the residual bar chart $\left(N_{\text {exp }}-N_{\text {theor }}\right)$. According to Pearson criterion, the obtained sample at the significance level $\alpha=0.05$ corresponds to the normal distribution with zero mathematical expectation, all values falling within the interval $[-3 S ; 3 S]$, where $S=85.16$ is the corrected standard root-mean-square deviation of the residuals. Then $77 \%$ of the residues fall into the interval $[-S ; S]$, while $95 \%$ - in the interval $[-2 S ; 2 S]$.

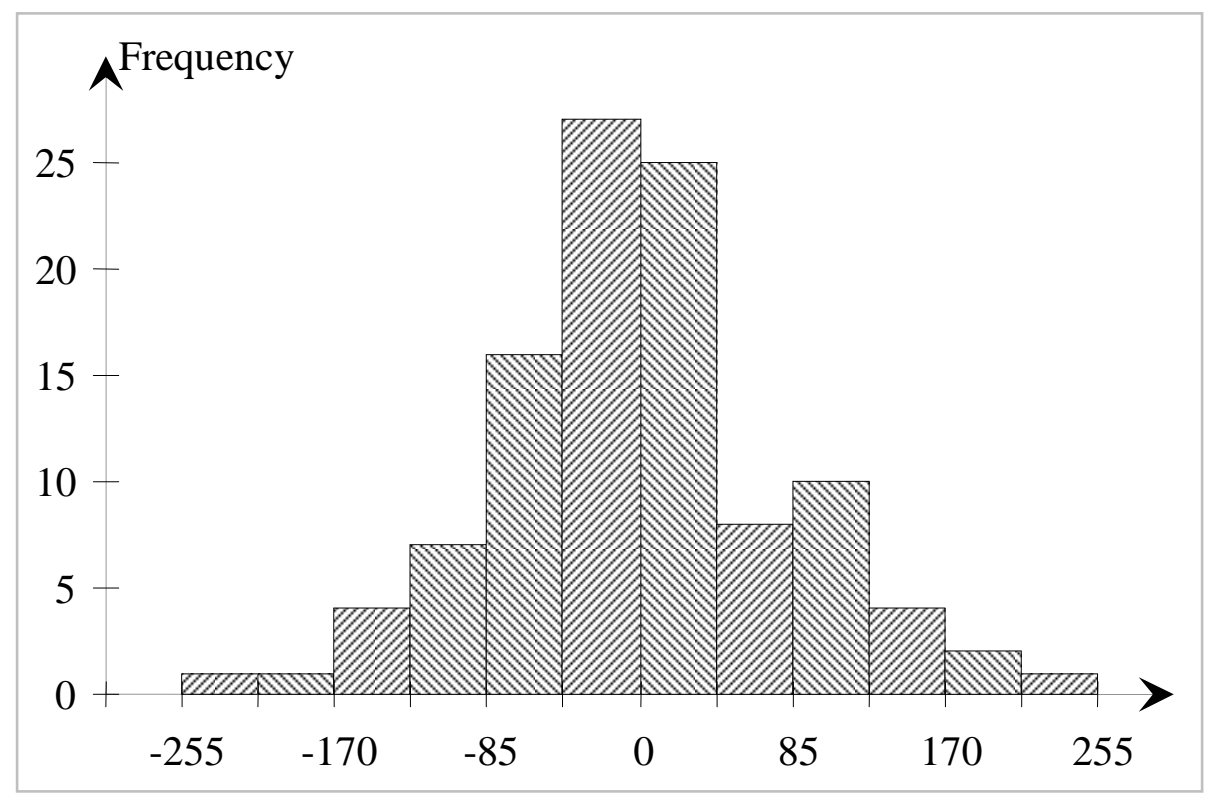

Fig. 1: Residual bar chart. columns.

Fig. 2 shows the experimental and estimated data on the carrying capacity values of the 


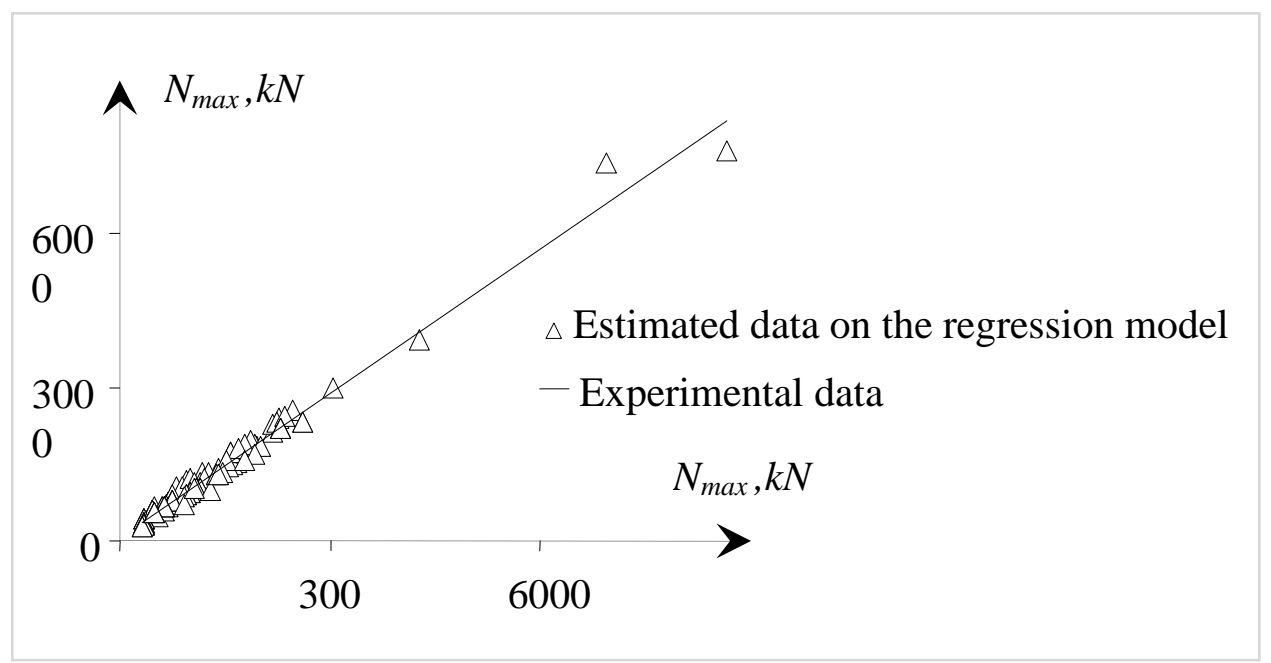

Fig. 2: Carrying capacity of columns. shown in Fig. 3.

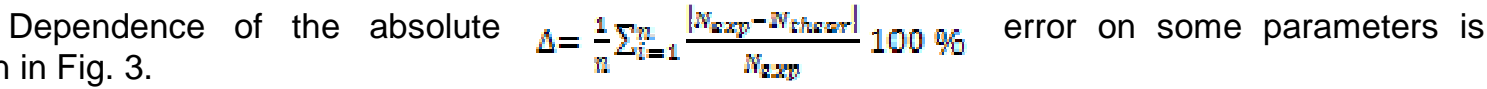

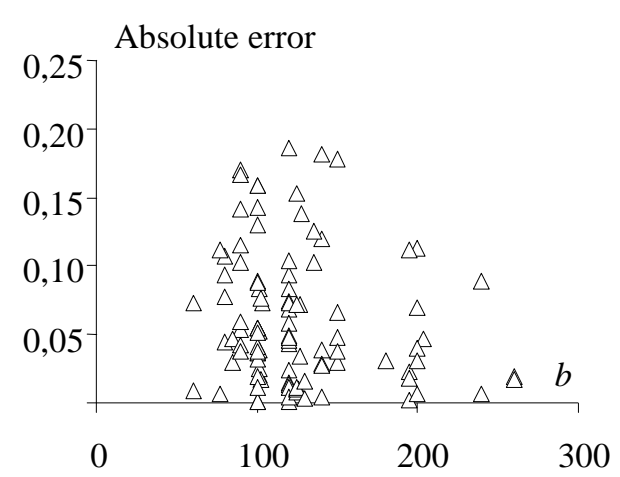

a)

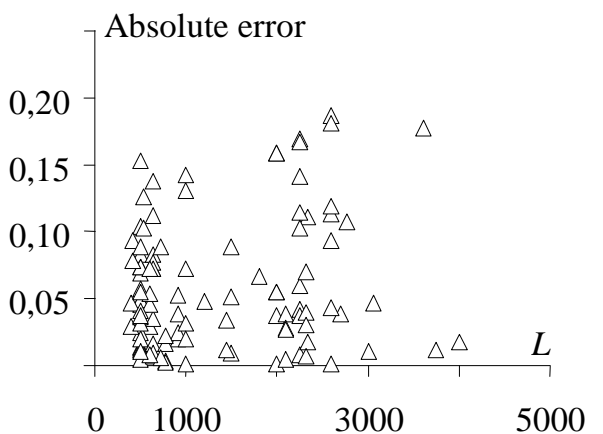

c)

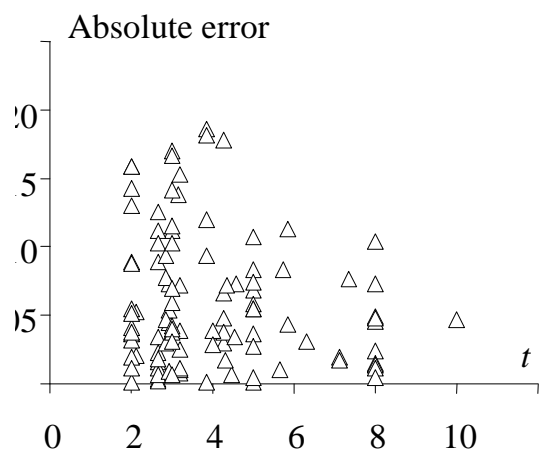

b)

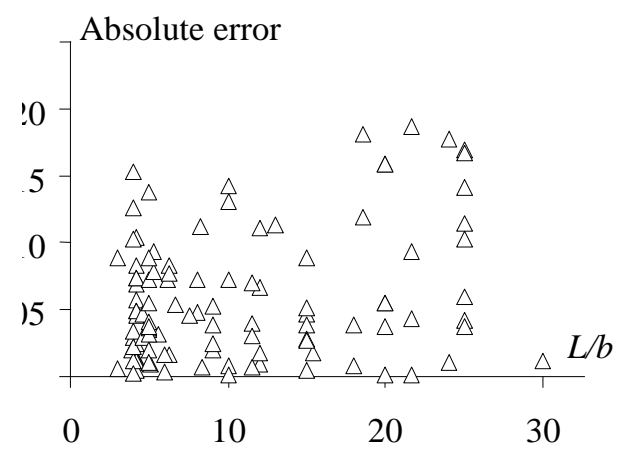

Fig. 3: Dependence of the absolute error of the regression model: a) on $b$; b) on casing thickness $t$; c) on column length $L ;$ d) on the value $L / b$.

The analysis of regression model factors shows that the first term $b h f_{c, p r i z m}$ makes the major contribution to the carrying capacity value of composite columns (Fig. 4). 


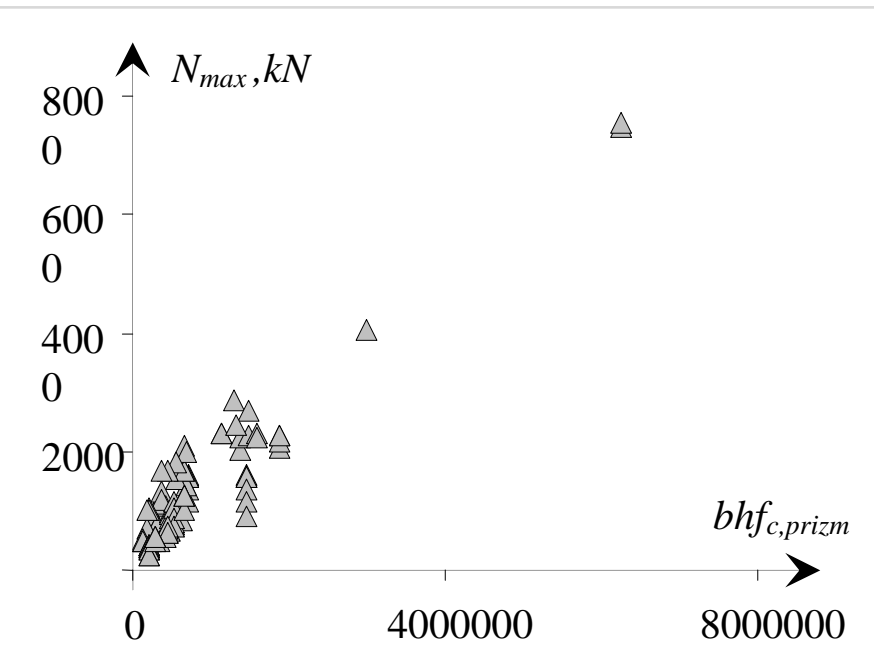

Fig. 4: Dependence between the maximum carrying capacity value and the value $b h f_{c, p r i z m}$.

Such dependence is well approximated by the linear function $y=0.0011 x+442.73$ and gives the determination coefficient $R^{2}=0.886$. Thus, we can state that $89 \%$ of the change in the carrying capacity is due to the combined influence of the cross-sectional area and the prism strength value of the concrete, however, this is insufficient to obtain a more accurate overview of the behavior of the columns, therefore, take into account other characteristics (length, yield strength of steel, modulus of elasticity of steel and concrete) and their combined influence should be taken into account.

The developed model enables to estimate the degree of influence of the parameters of rectangular composite columns on the carrying capacity value. Thus, the maximum carrying capacity increased in average by $5.7 \%$, when the casing thickness increased by $10 \%$, and by $7.59 \%$ when the cross-sectional area of the column increased by $10 \%$.

Fig. 5 below shows the dependence of the growth of the carrying capacity (\%) with the increase of the casing thickness by $10 \%$ for different characteristics of the columns.

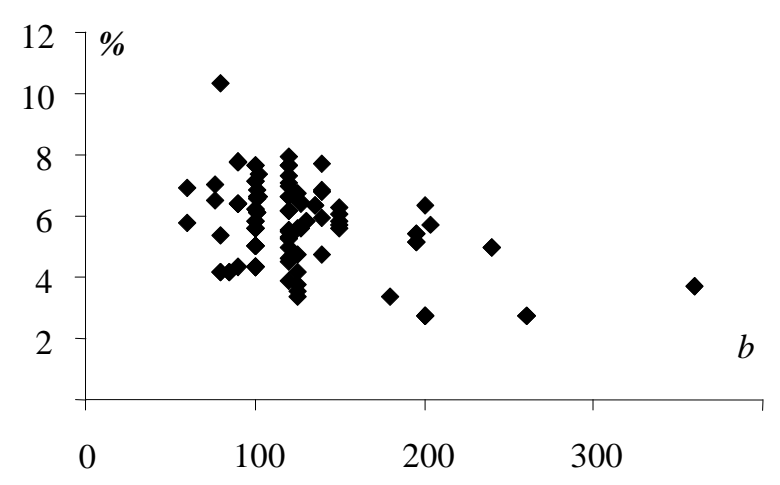

a)
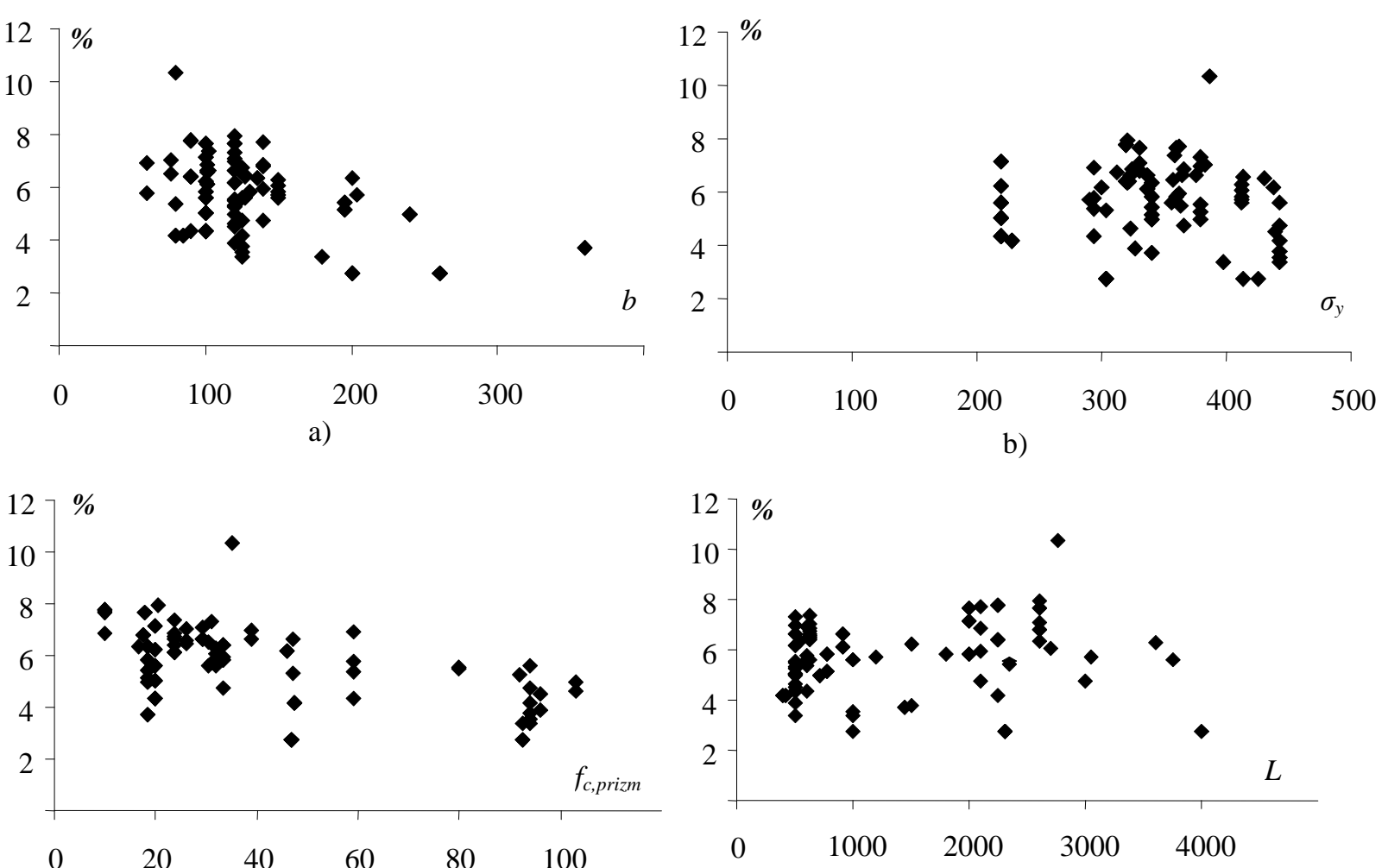

c)

d)

Fig. 5: Change of the carrying capacity (\%) with the increase of the casing thickness by $10 \%$. 
It can be seen in Fig. 5 that the increase of the casing thickness by $10 \%$ in some cases may result in the increase of the carrying capacity of the column up to $10.5 \%$.

Three series of steel columns 500,1000,1500, and $2000 \mathrm{~mm}$ length were experimentally tested to verify the conducted analytical studies. The column casings with a thickness $t=2 \mathrm{~mm}$ were filled with $\mathrm{C} 16 / 20$ concrete.

The used testing technique, the accepted measuring instruments and their placement layouts allowed obtaining the necessary objective experimental data on the carrying capacity, development of deformations, and the nature of the destruction of the samples. The experimental studies were performed in accordance with the relevant regulatory recommendations.

The materials (steel and concrete) used for the manufacturing of samples had physical and mechanical properties that were characteristic of the materials widely applied in designing real building structures.

The steel casing for the experimental samples was made of two cold rolled steel sheets $2 \mathrm{~mm}$ thick, bent in the shape of channels and welded along the entire length with semi-automatic welding. The casings was manufactured of $08 \mathrm{kp}$ steel with a yield point $f_{y} \sigma_{y}=240 \mathrm{MPa}$.

Once metal casings were manufactured, they were filled with a concrete mixture in the upright position with a layer-by-layer compaction on the vibrating platform. Concrete filling was of class $\mathrm{C} 20 / 25$. Next to the compaction, the open surface of the concrete was carefully evened. During the first 28 days, the open concrete surfaces were moistened and covered with a film to keep the moisture. The test samples were stored in the laboratory room at a temperature from $+18^{\circ} \mathrm{C}$ to +24 ${ }^{\circ} \mathrm{C}$ and relative humidity of $75 \%$. After the concrete gained the design strength (in 28 days), the concrete surface was grinded and covered with the metal casing to ensure the full contact with the press plate.

The following marking of the test samples which were tested for the centric compression was accepted for the experiment:

-SBK - 1, 2, 3, 4; SBK - 1.0-1, 2, 3; SBK - 1.5-1, 2; SBK - 2.0-1, 2 - square steel-concrete columns $100 \times 100 \mathrm{~mm}$;

- SBP - 1, 2, 3, 4 - rectangular steel-concrete columns $150 \times 100 \mathrm{~mm}$.

The steel-concrete columns were tested using the hydraulic press IP-2000 in the laboratory of the Department of Structural Mechanics and Hydraulics of the Ukraine State University of Railway Transport.

Axial load on the complex cross-section was applied to the samples.

All samples were tested to failure. Appearance of the steel-concrete columns before testing is shown in Fig. 6.

a)

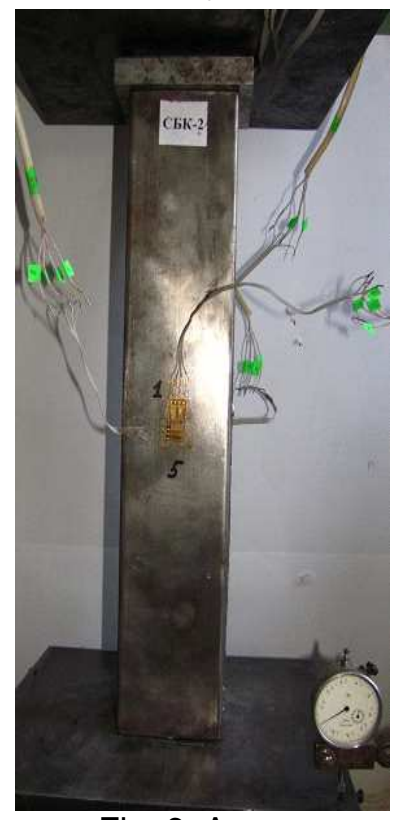

b)

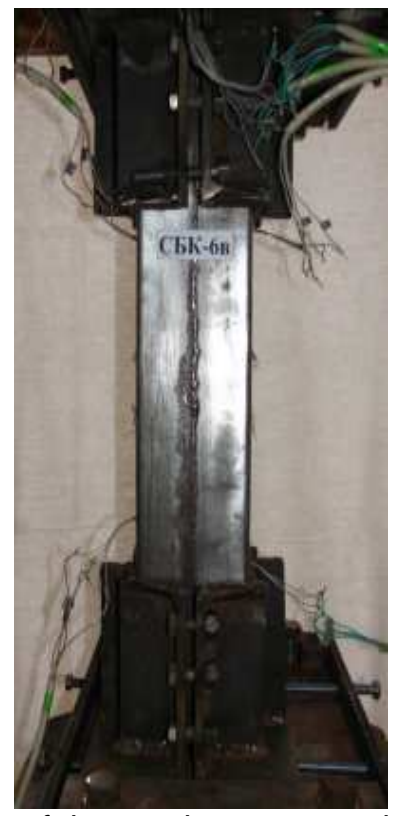

c)

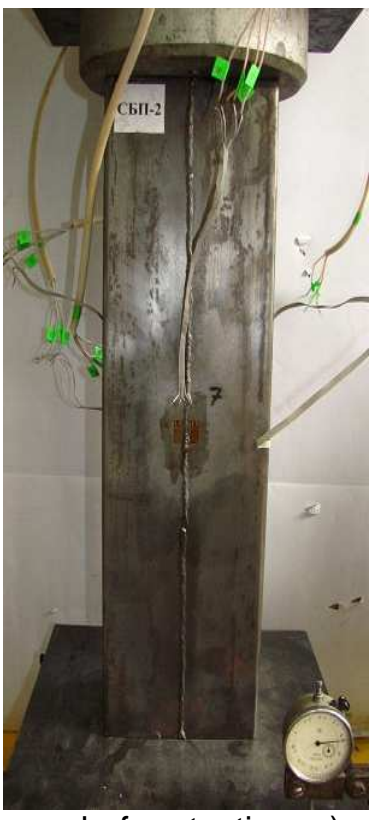

d)

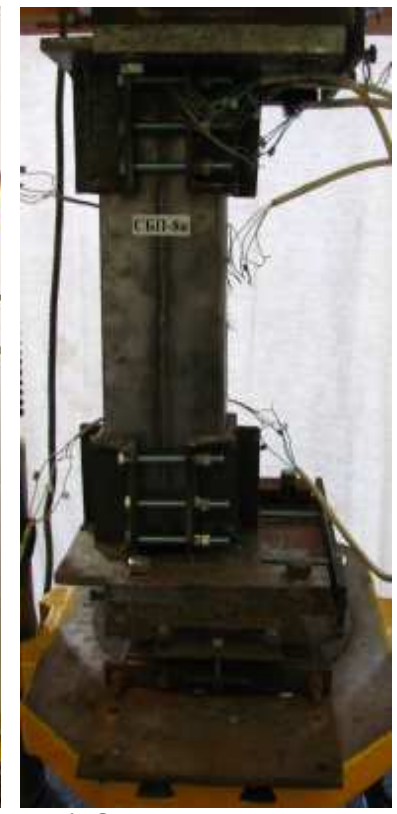

Fig. 6: Arrangement of the steel-concrete columns before testing: a) and b) SBK columns;

c) and d) SBP columns. 
During the experiment, two stresses were recorded that correspond to different criteria of the loss of the carrying capacity. The first stress corresponded to the achievement of the yield point of the casing steel $\left(N_{y}\right)$, which was determined by the strain gauge readings in the maximally compressed area, while the second stress was the maximum load that the sample could withstand $\left(N_{u}\right)$. The second stress was characterized by a constant load on the scale of the weighing device and by large longitudinal deformations in the columns. In the analysis of the obtained results, the coefficient of conditional reliability of the concrete element $\psi$ was introduced, which is equal to the ratio $N_{y} / N_{u}$. The results of tests of the steel-concrete columns are summarized in Table 1.

Table 1: Results of tests of the steel-concrete columns.

\begin{tabular}{|c|c|c|c|c|c|c|c|c|c|c|c|}
\hline Sample No. & $\begin{array}{c}\boldsymbol{L} \\
{[\mathbf{m m}]}\end{array}$ & $\begin{array}{c}\boldsymbol{e}_{\mathbf{0}} \\
{[\mathbf{m m}]}\end{array}$ & $\begin{array}{c}\boldsymbol{N}_{\boldsymbol{y}} \\
{[\mathbf{k N}]}\end{array}$ & $\begin{array}{c}\boldsymbol{N}_{\boldsymbol{u}} \\
{[\mathbf{k N}]}\end{array}$ & $\boldsymbol{\psi}$ & Sample No. & $\begin{array}{c}\boldsymbol{L} \\
{[\mathbf{m m}]}\end{array}$ & $\begin{array}{c}\boldsymbol{e}_{\mathbf{0}} \\
{[\mathbf{m m}]}\end{array}$ & $\begin{array}{c}\boldsymbol{N}_{\boldsymbol{y}} \\
{[\mathbf{k N}]}\end{array}$ & $\begin{array}{c}\boldsymbol{N}_{\boldsymbol{u}} \\
{[\mathbf{k N}]}\end{array}$ & $\boldsymbol{\psi}$ \\
\hline SBK - 1 & 500 & 0.0 & 211 & 400 & 0.53 & SBP -1 & 500 & 0 & 354 & 498 & 0.71 \\
\hline SBK - 2 & 500 & 0.0 & 257 & 395 & 0.65 & SBP -2 & 500 & 0 & 366 & 548 & 0.67 \\
\hline SBK - 3 & 500 & 0.0 & 318 & 425 & 0.75 & SBP - 3 & 500 & 0 & 428 & 560 & 0.76 \\
\hline SBK - 4 & 500 & 0.0 & 307 & 402 & 0.76 & SBP - 4 & 500 & 0 & 435 & 563 & 0.77 \\
\hline
\end{tabular}

Fig. 7 shows the steel-concrete columns after testing. It should be noted that the test samples did not lose their carrying capacity instantly, which is typical for steel-concrete structures. Even receiving considerable deformations, they still were sustaining heavy load for a long time.

a)

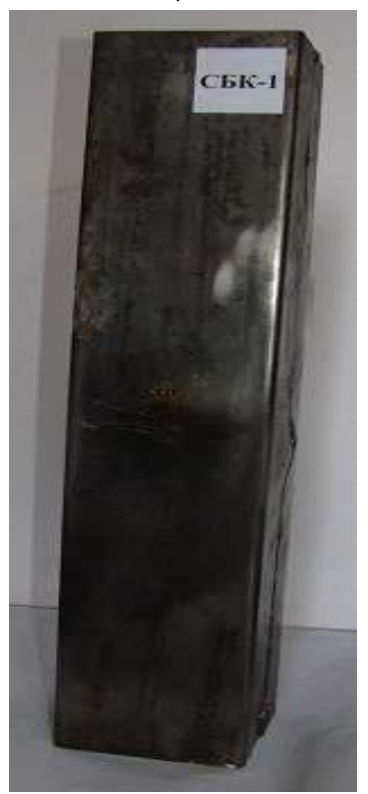

b)

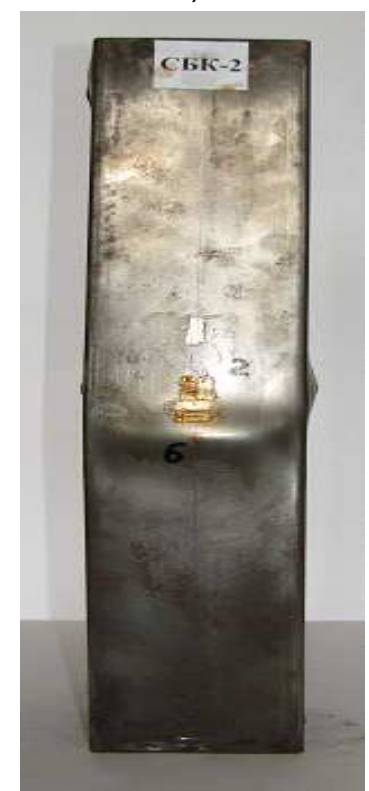

c)

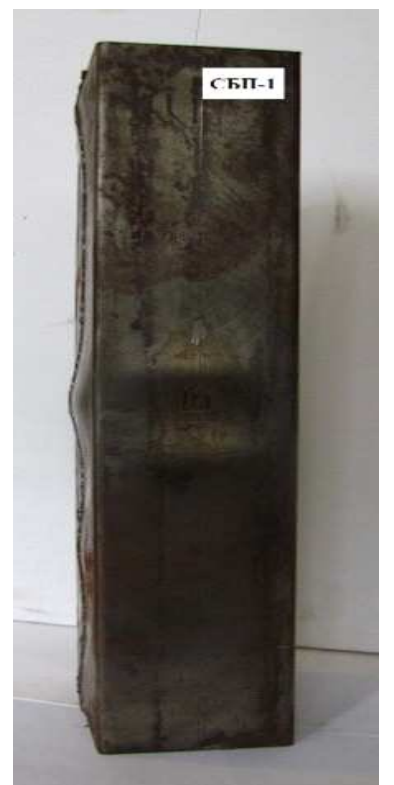

d)

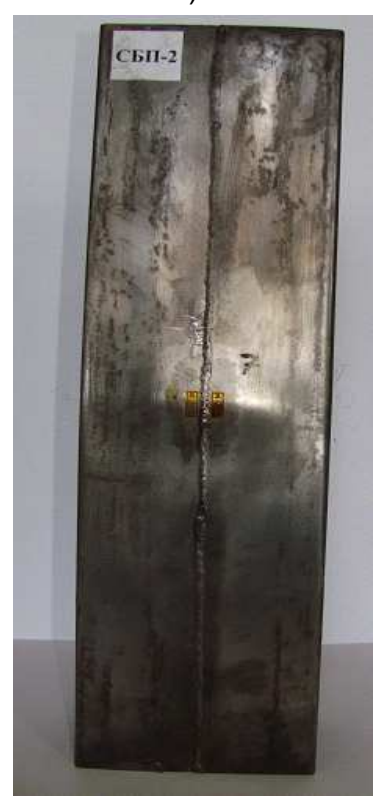

Fig. 7: Steel-concrete columns after testing: a) and b) SBK columns; c) and d) SBP columns.

After the dismantling of the steel column casing, the nature of the destruction of the concrete core was analyzed. The appearance of the concrete core and the steel casing after the dismantling of the columns is shown in Fig. 8. It can be seen in the figure that in the places of partial (local) destruction of the concrete core, the concrete is detached from the casing, at this moment a sharp redistribution of stresses between the components of the steel-concrete element occurs resulting in the loss of stability of the steel casing and appearance of buckles. 
a)

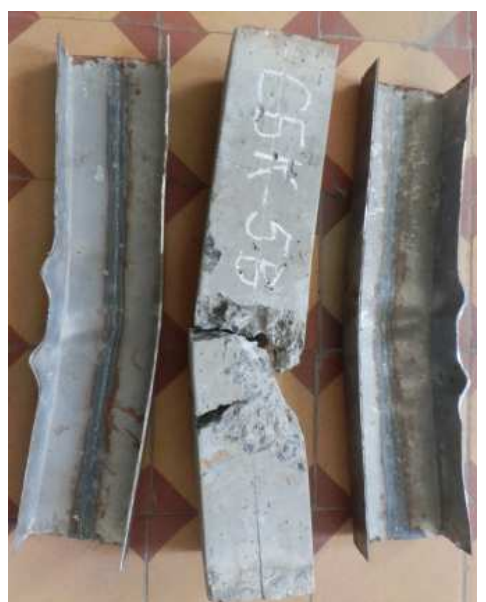

b)

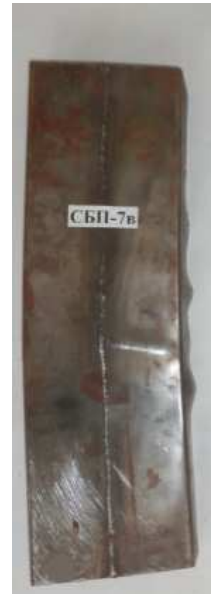

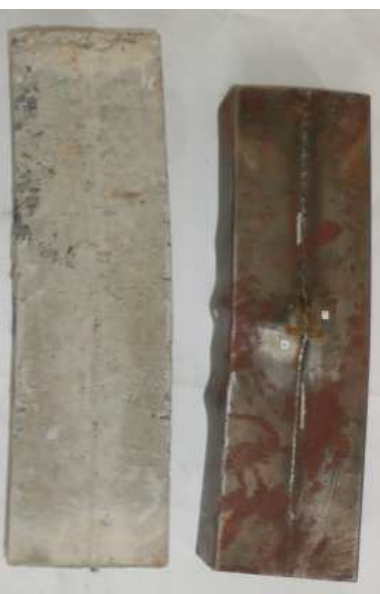

C)

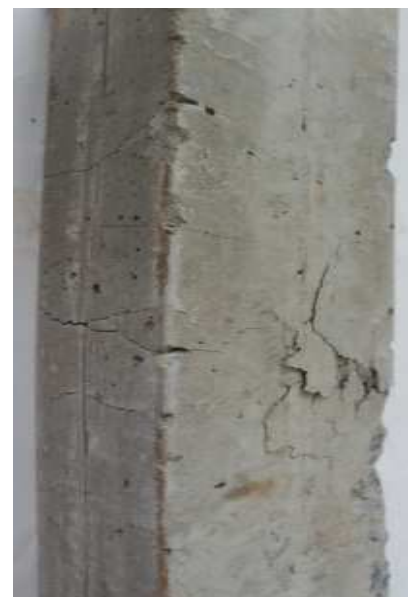

Fig. 8: Appearance of the concrete core and the steel casing after dismantling of the columns: a) square column; b) and c) rectangular column.

The nature and type of destruction of eccentrically compressed samples were generally similar to those of the destruction of centrically compressed steel-concrete elements.

In the first phase, the elastic behavior of the concrete core and the steel casing was recorded. The increment in deflections and deformations in the cross-sectional area of the average height was almost proportional to the load increment.

In the second (elastic plastic) phase, the yield of the casing metal in the compressed area was observed. Dependences of deformations and deflections on the load became nonlinear. When the longitudinal strains in the steel casing reached values of about $(1000 \div 1200) \cdot 10^{-6}$, the elastic plastic phase of the behavior of the samples ended.

In the third (plastic) phase, longitudinal and transverse deformations of the element increased drastically. In the plastic phase of behavior of steel-concrete samples, most of the strain gauges placed in the compressed area were destroyed due to excessively large deformations of concrete and steel.

In Table 2 the comparative analysis of the experimental $N_{\text {exp }}$ and theoretical $N_{\text {theor }}$ results obtained by the authors, as well as the calculations conducted in accordance with Eurocode 4 are summarized.

Table 2: Comparative analysis.

\begin{tabular}{|c|c|c|c|c|c|c|}
\hline Sample No. & $L[\mathrm{~mm}]$ & $N_{\exp }[\mathrm{kN}]$ & $N_{\text {theor }}[\mathrm{kN}]$ & $\Delta[\%]$ & EC4 & $\Delta[\%]$ \\
\hline SBK - 1 & 500 & 400 & 416.57 & 3.98 & 357 & 12.04 \\
\hline SBK - 2 & 500 & 395 & 416.57 & 5.18 & 357 & 10.64 \\
\hline SBK - 3 & 500 & 425 & 416.57 & 2.02 & 357 & 19.05 \\
\hline SBK - 4 & 500 & 402 & 416.57 & 3.50 & 357 & 12.61 \\
\hline SBK - 1.0-1 & 1000 & 426 & 370.42 & 15.00 & 348 & 22.41 \\
\hline SBK - 1.0-2 & 1000 & 432 & 370.42 & 16.62 & 348 & 24.14 \\
\hline SBK - 1.0-3 & 1000 & 370 & 370.42 & 0.11 & 348 & 6.32 \\
\hline SBK - 1.5-1 & 1500 & 356 & 324.26 & 9.79 & 334 & 6.59 \\
\hline SBK - 1.5-2 & 1500 & 342 & 324.26 & 5.47 & 334 & 2.40 \\
\hline SBK - 2.0-1 & 2000 & 240 & 278.11 & 13.70 & 315 & 23.81 \\
\hline SBK - 2.0-2 & 2000 & 240 & 278.11 & 13.70 & 315 & 23.81 \\
\hline SBP - 1 & 500 & 498 & 542.03 & 8.12 & 497 & 0.20 \\
\hline SBP - 2 & 500 & 548 & 542.03 & 1.10 & 497 & 10.26 \\
\hline SBP - 3 & 500 & 560 & 542.03 & 3.32 & 497 & 12.68 \\
\hline SBP - 4 & 500 & 563 & 542.03 & 3.87 & 497 & 13.28 \\
\hline
\end{tabular}




\section{Conclusions}

1. Data on the nature of the development of longitudinal and transverse deformations on the surface of the steel casing and inside the concrete core at different stages of loading were obtained as a result of testing of steel columns. The experimental studies have revealed the influence of thee geometric dimensions and the physical and mechanical characteristics of the used materials of steelconcrete columns on their carrying capacity and deformability.

2. The analytical dependence of the maximum carrying capacity of rectangular composite columns under centric compression is obtained, which enables to evaluate the effect of the geometric and physical characteristics of the column on the carrying capacity.

3. The comparative analysis of the theoretical and experimental results confirms a sufficiently high reliability of the obtained model.

\section{References}

[1] CHIKHLADZE, E. D. - VATULIA, G. L. - KITOV, Y. P.: Basis for calculation and design of composite and steel-concrete constructions. Transport of Ukraine, 104, 2006.

[2] VATULIA, G. L.: Design and construction of steel concrete and combined structures. Dissertation, Kharkiv, 409, 2015 (in Ukrainian).

[3] YAMAMOTO, T.: Experimental study of the size effect on the behaviour on concrete filled circular steel tube columns under axial compression. Journal of Structural and Construction Engineering (Transactions of AlJ), Vol. 67, Iss. 561, 2002, pp. 237 - 244.

[4] KRISHAN, A. L. - MELNITCHUK, A. S.: Strength and deformability of short tube confined concrete columns of square cross section. The News of KSUAE, Kazan, Vol. 3, Iss. 29, 2014, pp. 6 - 50.

[5] STOROZHENKO, L. I. - ERMOLENKO, D. A. - LAPENKO, O. I.: Tube confined concrete. ASMI, LLC, Poltava, 306, 2010.

[6] NISHIYAMA, I. - MORINO, S. - SAKINO, K. - NAKAHARA, H.: Summary of Research on CFT Column System Carried Out under the U.S. - Japan Cooperative Research on Composite and Hybrid Structures. Tokyo, 2002.

[7] Design of composite steel and concrete structures - Part 1-1: General Rules and Rules for Bridges. EN 1994-1: 2001. Eurocode 4, Brussels, 96, 2006.

[8] VATULIA, G. L. - PETRENKO, D. H. - NOVIKOVA, M. A.: Experimental estimation of load-carrying capacity of circular, square and rectangular CFTS columns. Scientific Bulletin of National Mining University, Iss. 6, 2017, pp. 97 - 102.

[9] VATULIA, G. - REZUNENKO, M. - OREL, YE. - PETRENKO, D.: Regression equations for circular CFST columns carrying capacity evaluation. DYN - WIND' 2017, MATEC Web of Conferences, Vol. 107, article No. 00051, 2017. 